\title{
INFLUENCE OF METABOLIC CAGE ON WISTAR RAT PHYSIOLOGICAL STATE
}

\author{
Judita Zymantiene, Rasa Zelvyte, Vaidas Oberauskas, Ugne Spancerniene \\ Department of Anatomy and Physiology, Veterinary Faculty of Lithuanian University \\ of Health Sciences, Tilzes st. 18, LT 47181 Kaunas, Lithuania
}

Received 16 June 2015; Received in revised form 24 September 2015; Accepted 12 October 2015

\begin{abstract}
The aim of this study was to investigate the influence of metabolic cage housing on the Wistar rat physiological state and to analyze the correlation between the minerals in blood and urine. Thirty male rats were used in the experiment. Fifteen rats (control group) were housed individually in standard polycarbonate cages and fifteen rats (experimental group) in metabolic cages (Techniplast, Italy) for two weeks. Body weight, respiration rate, water and food consumptions were recorded for each animal at the beginning of the experiment. The same parameters, as well as blood and urine parameters of control and experimental animals were recorded during the experiment after $72 \mathrm{~h}, 168 \mathrm{~h}$ and $336 \mathrm{~h}$ of housing in standard cages and metabolic cages. Urine collection was measured only in the experimental group. Rats weight decreased from $3.84 \%$ to $18.59 \%$ $(\mathrm{P}<0.05)$, respiration rate from $18.65 \%$ to $24.59 \%(\mathrm{P}<0.05)$ when rats were housed in metabolic cages. Consumption of food and water by the rat depended on how long the animal was kept in metabolic cage. Glucose concentration increased on average by $15.37 \%$, WBC count decreased by $5.83 \%$ in the blood of rats housed in metabolic cages compared to the animals housed in standard cages. We did not observe significant changes of triglycerides concentration, red blood cells count and total protein between all rats. The positive moderate correlation of rat housing in a metabolic cage was between $\mathrm{K}$ blood and $\mathrm{K}$ urine, $\mathrm{P}$ blood and $\mathrm{P}$ urine, Na blood and $\mathrm{K}$ blood, between Na urine and $\mathrm{P}$ urine and significant negative moderate correlation was determined between $\mathrm{K}$ urine and $\mathrm{P}$ urine. These present study findings indicate that metabolism cage housing significantly affects rat's physiological parameters and potentially may influence animal health and wellbeing.
\end{abstract}

Key words: metabolic cage, rat, blood, urine, physiological parameters

\section{INTRODUCTION}

Rodents are mostly used in scientific and experimental studies. Rats are one of the primary mammalian species used for the evaluation of acute and chronic toxicity, metabolism and bioavailability in preclinical evaluation of drugs and preregistration evaluation of chemicals $(1,2)$. Rats are used for metabolism study, pharmacokinetic study, toxicity testing, vaccine potency testing, model for induction of tumors and etc. (3).

Metabolic cages are used to gain information about metabolic function and how different factors

Corresponding author: Dr. Zymantiene Judita, $\mathrm{PhD}$

E-mail address: Judita.Zymantiene@1smuni.lt

Present address: Department Anatomy and Physiology,

Lithuanian University of Health Sciences, Tilzes 18, Kaunas LT-47181

Phone: +370 37 363204; Fax: +370 37 327200/+370 37220733

Copyright: (C) 2015 Zymantiene J. This is an open-access article published under the terms of the Creative Commons Attribution License

which permits unrestricted use, distribution, and reproduction in any medium, provided the original author and source are credited. Competing Interests: The authors have declared that no competing interests exist.

Available Online First: 4 November 2015

Published on: 15 March 2016

http://dx.doi.org/10.1515/macvetrev-2015-0062 affect animal's metabolism processes $(2,4)$. Metabolic cages are equipped with a unique system for the separated collection of faeces and urine. The cage is designed to avoid contamination of the urine and effectively separate urine and faeces into collection tubes outside of the cage (2). The grid floor is a necessity to allow urine and faeces to be collected $(5,6)$.

Design and finish results are such that the animal has a minimum of comfort and housing on grid floors is negative for animal welfare. Preference tests have shown that most rats prefer to sleep in solid bottom cages (7). Rodents housed in metabolic cages can not perform some of their natural behaviors such as nest-building, hiding, social interaction process (8). Social isolation affected the central nervous system of mice and single housed wild type mice showed an increase of stereotypic behaviors which strongly indicate a lack of possibilities to perform natural behaviors in the environment $(9$, 10). Moreover, social isolation, lack of nesting material, housing on grid floor and small cage area are environmental factors that may expose rodents 
to stress (8). Conducted surveys revealed that grid floor can cause hypersensitivity and nerve injury in the feet of rats and lead to elevated corticosterone levels, increased blood pressure, heart rate and body temperature.

There are limited scientific investigations performed on the influence of a metabolic cage on animal welfare. Stress can be defined as factor that alters the internal environment of the body (11). The body has some major adaptations to stress in order to maintain homeostasis, prepare for physical activity, such as increased glucocorticoid and catecholamine secretion $(12,13)$. According to scientists observations it was measured that young male rats housed in metabolic cages had reduced weight gains and produced more amounts of faeces after three days of metabolism cage housing (4). There are various reasons how the type of cage influences weight of rodents. Single housed mice had significantly lower body weights and lower bone mineral content, compared to animals held in groups. Some researches noticed several physiological disruptions due to increased levels of circulating corticosterone in single housed rodents $(14,15)$. Many scientists conducted studies on social isolation and the release of sympathetic neurotransmitter substances in the brains of mice. Since the reproductive, cardiovascular, gastrointestinal and the immune system are regulated by the sympathetic nervous system any change in the central nervous system will have great impact on the animal's physiology (16). Attempts to keep rodents in metabolic cages have been carried out in all EU countries, but some researchers noticed only changes in animals behavior, others $(2,8,10,17)$ determined only changes of hormonal activity in blood or lower animals weight, but there is still insufficient knowledge about systematic data changes of physiological parameters.

The aim of this study was to investigate the influence of metabolic cage housing on Wistar rat physiological state and to analyze the correlation between minerals in blood and urine.

\section{MATERIAL AND METHODS}

24-weeks-old male Wistar rats weighing $289.05 \pm 1.55 \mathrm{~g} \quad($ mean \pm SEM (standard error of the mean)) were used. The rats were kept under normal conditions: light-dark cycle of 12:12 hours, temperature maintained at $22 \pm 2^{\circ} \mathrm{C}$ and relative humidity was $55 \pm 5 \%$. Rats were given ad libitum access to high-quality feed of the same batch and water throughout the whole study in both groups. The commercial standard diet (PA-11700000-171) 34 for rodents contained crude protein $19.91 \%$, fat $12.05 \%$, crude fiber $2.79 \%$ and $7.72 \%$ cellulose in $1 \mathrm{~kg}$ of feed. All procedures were approved by the local Animal Ethical Committee (No. license G2-16).

A control group of fifteen rats were housed individually in standard polycarbonate cages (Techniplast, Italy), where minimum enclosure size was $800 \mathrm{~cm}^{2}$, floor area per animal $350 \mathrm{~cm}^{2}$ and minimum $18 \mathrm{~cm}$ height according to the Directive 2010/63 EU of the European Parliament and of the Council of 22 September 2010 on the protection of animals used for scientific purposes. Fifteen rats of the experimental group were transferred to and housed in individual metabolic cages (Techniplast, Italy) with stainless steel grid floor for two weeks.

Body weight, respiration rate, water and food consumptions were recorded for each animal in the beginning of the experiment. The same parameters as well as blood and urine parameters of control and experimental animals were recorded during the experiment after $72 \mathrm{~h}, 168 \mathrm{~h}, 336 \mathrm{~h}$ of housing in standard cages and metabolic cages. Urine collection was measured only in the experimental group. Rats were weighed using the scales KERN PCB000-1 (Germany, 2014). Daily urine was collected at 9 a.m. for analysis and calculation of diuresis intensity. Water and food consumption were calculated via 24 hours. Respiration rate was measured by calculation of breaths per minute. The rats were killed by an overdose of carbon dioxide in camber and blood samples were collected from v. jugularis.

Blood samples collected in heparinized tubes were used for determination of red blood cells (RBC) and white blood cells (WBC) count. RBC and WBC count were calculated using hemacytometer Neubauer chamber (Germany) under the microscope OLYMPUS CX 22LED (Germany).

Serum was separated taking blood in microtubes without anticoagulant, using rotation $4000 \mathrm{x} \mathrm{g}$ for 10 min by centrifuge (EBA-200, Germany). Serum levels of glucose (GL), triglycerides (TG) and total protein (T-Pro) were measured by analyzer SPOTCHEM EZ SP-4430 (Arkray Inc., Japan).

The concentrations of minerals as sodium $(\mathrm{Na})$, potassium $(\mathrm{K})$, phosphorus $(\mathrm{P})$ in serum and urine after $336 \mathrm{~h}$ housing in metabolic cages were assayed using Cobas Integra 400 plus analyzer and commercial kits (Tegimenta Ltd Roche, Switzerland).

The statistical analysis of the results were carried out using the SPSS (licence No. 9900457; version 15, SPSS Inc., Chicago, IL). All data are presented as mean \pm SEM. The level of statistical significance was set at $\mathrm{P}<0.05$. Correlation coefficient ( $r$ ) was used for measuring the relationship between two 
Influence of metabolic cage on rat physiological state

variables. The correlation is considered weak at $\mathrm{r}=0.50$, moderate at $\mathrm{r}=0.50-0.75$ and strong at $\mathrm{r}=0.80-1.00$.

\section{RESULTS}

At the beginning of the experiment body weight, respiration rate, consumption of food and water of control and experimental rats were similar within the range of the physiological norms for rats (Table 1). Variation of some functional parameters of the rats during the study have been presented in Table 2 . Duration of the housing of rats in the metabolic cage influenced the body weight and respiration rate. Rats weight decreased $3.84 \%$ and $18.59 \%(\mathrm{P}<0.05)$ respectively when rats were housed $72 \mathrm{~h}$ and 168 hours in metabolic cages, compared to the housing of animals in standard cages. We did not determine changes in breathing when rats were housed $72 \mathrm{~h}$ in metabolic cages, but the respiration rate decreased from 18.65 to $24.59 \%(\mathrm{P}<0.05)$ when rats were housed from 168 to 336 hours in metabolic cages compared to the rats housed in the standard cages. We established a tendency of increasing water consumption by average of $37.68 \%(\mathrm{P}<0.01)$ when rats were housed $168 \mathrm{~h}$ and 336 hours in metabolic cages, but there were no changes when rats were 72 hours in these cages. The intensity of diuresis increased from $6.19 \%$ to $28.32 \%$ after $168 \mathrm{~h}$ and $336 \mathrm{~h}$ of housing rats in metabolic cages compared to the diuresis of rats after $72 \mathrm{~h}$ of housing in metabolic cages.

In vivo study in rats has demonstrated that metabolic cages have influence on the GL concentration in blood (Table 3). Glucose level increased from 13.95 to $16.79 \%$ in blood of rats housed in metabolic cages compared to the rats housed in standard cages. Our experiment results did not reveal any significant changes of TG concentration, $\mathrm{RBC}$ and total protein counts between all rats, but WBC decreased by average $5.83 \%$ (from 5.00 to $6.33 \%$ ) $(\mathrm{P}<0.05)$ in the blood of rats housed in metabolic cages compared to the analogical parameters of housing rats in standard cages.

Table 1. Body weight, respiration rate, consumption of food and water of control and experimental rats at the beginning of the study

\begin{tabular}{lcc}
\hline \multirow{2}{*}{ Parameter } & \multicolumn{2}{c}{ Group } \\
\cline { 2 - 3 } & Control, $\mathbf{n = 1 5}$ & Experimental, $\mathbf{n = 1 5}$ \\
\hline Body weight, $\mathrm{g}$ & $288.5 \pm 1.8$ & $289.6 \pm 1.3$ \\
Respiration rate, breaths $/$ min & $60.0 \pm 2.3$ & $60.0 \pm 1.4$ \\
Consumption of water, via $24 \mathrm{~h}, \mathrm{ml}$ & $25.0 \pm 1.7$ & $24.0 \pm 1.5$ \\
Consumption of food, via $24 \mathrm{~h}, \mathrm{~g}$ & $39.7 \pm 2.1$ & $41.2 \pm 1.9$ \\
\hline
\end{tabular}

Table 2. Variations of rats' body weight, respiration rate, consumption of food and water and intensity of dieresis

\begin{tabular}{|c|c|c|c|c|c|c|}
\hline \multirow[b]{2}{*}{ Parameter } & \multicolumn{3}{|c|}{ Control group } & \multicolumn{3}{|c|}{ Experimental group } \\
\hline & after $72 \mathrm{~h}$ & after $168 \mathrm{~h}$ & after $336 \mathrm{~h}$ & after $72 \mathrm{~h}$ & after $168 \mathrm{~h}$ & after $336 \mathrm{~h}$ \\
\hline Number, $\mathrm{n}$ & 5 & 5 & 5 & 5 & 5 & 5 \\
\hline Body weight, $g$ & $288.7 \pm 1.4^{*}$ & $288.4 \pm 1.7^{*}$ & $289.3 \pm 2.3$ & $277.6 \pm 2.2 *$ & $234.8 \pm 1.5^{*}$ & $252.1 \pm 2.0$ \\
\hline $\begin{array}{l}\text { Respiration rate, } \\
\text { breaths/min }\end{array}$ & $60.0 \pm 1.9$ & $59.0 \pm 2.0 *$ & $61.0 \pm 1.8^{*}$ & $61.0 \pm 1.7$ & $48.0 \pm 1.9 *$ & $46.0 \pm 2.0^{*}$ \\
\hline $\begin{array}{l}\text { Consumption of } \\
\text { water, via } 24 \mathrm{~h}, \mathrm{ml}\end{array}$ & $25.6 \pm 2.1$ & $24.8 \pm 1.7 * *$ & $26.3 \pm 1.4^{* *}$ & $27.6 \pm 1.9$ & $40.0 \pm 1.5^{* *}$ & $30.0 \pm 1.8^{* *}$ \\
\hline $\begin{array}{l}\text { Consumption of food, } \\
\text { via } 24 \mathrm{~h}, \mathrm{~g}\end{array}$ & $37.2 \pm 2.3$ & $40.1 \pm 1.9$ & $39.2 \pm 2.3$ & $25.9 \pm 2.3$ & $25.0 \pm 1.8$ & $23.9 \pm 1.5$ \\
\hline $\begin{array}{l}\text { For a } 24-\mathrm{h} \text { intensity } \\
\text { of diuresis, } \mathrm{ml}\end{array}$ & - & - & - & $11.3 \pm 2.0$ & $14.5 \pm 2.2$ & $12.0 \pm 2.6$ \\
\hline
\end{tabular}

$\mathrm{P}<0.05^{*} ; \mathrm{P}<0.01 * *$ 
Zymantiene J. et al.

Table 3. Changes in some hematological parameters of rats

\begin{tabular}{|c|c|c|c|c|c|c|}
\hline \multirow[b]{2}{*}{ Parameter } & \multicolumn{3}{|c|}{ Control group } & \multicolumn{3}{|c|}{ Experimental group } \\
\hline & after $72 \mathrm{~h}$ & after $168 \mathrm{~h}$ & after $336 \mathrm{~h}$ & after $72 \mathrm{~h}$ & after $168 \mathrm{~h}$ & after $336 \mathrm{~h}$ \\
\hline Number, $\mathrm{n}$ & 5 & 5 & 5 & 5 & 5 & 5 \\
\hline $\mathrm{RBC}, \times 10^{12} / \mathrm{L}$ & $4.2 \pm 0.05$ & $4.0 \pm 0.15$ & $4.3 \pm 0.10$ & $4.3 \pm 0.07$ & $4.4 \pm 0.20$ & $4.2 \pm 0.14$ \\
\hline WBC, $\times 10^{9} / \mathrm{L}$ & $8.1 \pm 0.40^{*}$ & $8.0 \pm 0.31 *$ & $7.9 \pm 0.10^{*}$ & $7.6 \pm 0.51 *$ & $7.6 \pm 0.42 *$ & $7.4 \pm 0.09 *$ \\
\hline T-Pro, g/L & $56.3 \pm 0.84$ & $55.6 \pm 0.36$ & $55.7 \pm 1.00$ & $54.6 \pm 0.91$ & $54.8 \pm 0.88$ & $54.6 \pm 0.80$ \\
\hline $\mathrm{GL}, \mathrm{mmol} / \mathrm{L}$ & $6.88 \pm 0.10^{*}$ & $7.00 \pm 0.23$ & $6.79 \pm 0.33 *$ & $7.84 \pm 0.21^{*}$ & $7.38 \pm 0.17$ & $7.93 \pm 0.41 *$ \\
\hline $\mathrm{TG}, \mathrm{mmol} / \mathrm{L}$ & $1.62 \pm 0.08$ & $1.65 \pm 0.10$ & $1.63 \pm 0.15$ & $1.62 \pm 0.11$ & $1.72 \pm 0.07$ & $1.76 \pm 0.04$ \\
\hline
\end{tabular}

We found that when rats were housed 336 hours in metabolic cages there were changes in the main minerals in blood and urine and results are presented in Table 4. Correlation coefficient was used for measuring the relationship between the two variables. The positive moderate correlation was between $\mathrm{K}$ blood and $\mathrm{K}$ urine $(\mathrm{r}=0.7328 ; \mathrm{P}<0.01)$, $\mathrm{P}$ blood and $\mathrm{P}$ urine $(\mathrm{r}=0.6932 ; \mathrm{P}<0.01), \mathrm{Na}$ blood and $\mathrm{K}$ blood $(\mathrm{r}=0.6151 ; \mathrm{P}<0.01), \mathrm{Na}$ urine and $\mathrm{P}$ urine $(\mathrm{r}=0.7373 ; \mathrm{P}<0.01)$ and significant negative moderate correlation was determined between $\mathrm{K}$ urine and Purine.

Table 4. Correlations between blood and urine minerals of rats housed in the metabolic cages for $336 \mathrm{~h}$

\begin{tabular}{lll}
\hline & Parameter & r \\
\hline Na blood & Na urine & 0.0769 \\
\hline K blood & K urine & 0.7328 \\
\hline P blood & P urine & 0.6932 \\
\hline Na blood & K blood & 0.6151 \\
\hline Na blood & P blood & -0.1116 \\
\hline K blood & P blood & 0.2831 \\
\hline Na urine & K urine & -0.0083 \\
\hline Na urine & P urine & 0.7373 \\
\hline K urine & P urine & -0.5867 \\
\hline
\end{tabular}

We did not determine significant correlation between $\mathrm{Na}$ blood and $\mathrm{Na}$ urine; among $\mathrm{Na}$ blood and P blood, between P blood and $\mathrm{K}$ blood and among $\mathrm{Na}$ urine and $\mathrm{K}$ urine when rats were accommodated in a different cage system.

\section{DISCUSSION}

Modern housing technologies, physical environmental factors, research experiments, human interaction and intervention are parts of the stimuli presented to rats every day, influencing their physiology and contributing to their welfare. Human interaction, certain environmental conditions and routine procedures in the animal facility might induce stress responses and when the animal is unable to maintain its homeostasis in the presence of a particular stressor, the animal's wellbeing is threatened. When rats were housed in metabolic cages, the human interaction process increased because of daily urine collection and cage washing. The present study focused on the impact of the metabolic cage on the laboratory rat physiological state and correlation between minerals in blood and urine. When rodents are used in experiments with preclinical animal models they are kept in metabolic cages with specific floor construction and this fact can influence some functional parameters (18). Our results revealed that the long-term effect of housing of rats in a metabolic cages lead to changes in feeding, water consumption and some blood parameters compared to the housing of rats in standard cages. This may be associated with the specific construction of the cage floor that influences changes in the respiration rate of rats and this parameter decreased by $21.62 \%$. We established a tendency of increasing water consumption by $14.07 \%$ and decreasing of food consumption by $39.04 \%$ when rats were housed for 336 hours in metabolic cages. Scientists indicated that consumption of water and food depends on the bedding material volume (19), but in our experiment bedding was not provided. According to 
our analysis if the plate of the feeding area in the metabolic cage is not a very small grid construction, the rats are feeling better because they stand in a normal position. Some scientists identified that cage design and construction may influence temperature in the cage, which can affect the physiological state of the organism (20).

We determined that long-term housing of rats when this duration is applied in preclinical studies has negative effect on rats' functional parameters. After 7-14 days of rat's social isolation there was a significant decreased WBC count. Glucose concentration in blood, as one of the stress factors, depended on the duration of metabolic cage housing. We noticed that when rats were housed in metabolic cages from 168 to 336 hours, the glucose concentration increased by average of $15.37 \%$ if compared to the housing of animals in standard cages. Several authors have shown that cage cleaning promotes an acute stress response in laboratory animals $(10,21)$. They reported that cage cleaning of adult male Sprague-Dawley rats, housed in groups of three, elevated serum concentrations of corticosterone and prolactin $(15,22,23)$. We found that daily cleaning of metabolic cages and urine samples taking caused fear in rats. This effect showed that activation of the sympathetic nervous system has also been associated with routine housing procedures such as cage cleaning and significant increases in plasma noradrenalin and adrenalin (15, 24). Furthermore, we determined positive moderate correlation between $\mathrm{K}$ blood and $\mathrm{K}$ urine, $\mathrm{P}$ blood and $\mathrm{P}$ urine, $\mathrm{Na}$ blood and $\mathrm{K}$ blood, $\mathrm{Na}$ urine and $\mathrm{P}$ urine, but also significant negative moderate correlation was found between K urine and Purine.

Researchers should be careful with animal housing in metabolic cages when planning studies, because this modern cage caused potential discomfort due to floor construction, there is no place for rest and the animal does not have social communication.

\section{CONCLUSION}

Housing rodents in cages that exposes them to social isolation, or not natural grid floor construction, may cause physiological changes due to stress responses. But stress levesl depended on the duration of housing in a metabolic cage. Rats weight decreased from 3.84 to $18.59 \%(\mathrm{P}<0.05)$, respiration rate from 18.65 to $24.59 \%(\mathrm{P}<0.05)$ when rats were housed in a metabolic cage. Consumption of food and water of the rat depended on how long the animal was kept in a metabolic cage. Glucose concentration increased by $15.37 \%$,
WBC count decreased by $5.83 \%$ in the blood of rats housed in metabolic cages compared to the animals housed in standard cages. We did not observe significant changes in triglycerides concentration, red blood cells count and total protein between all rats. The positive moderate correlation in rats housed in metabolic cages was between $\mathrm{K}$ blood and $\mathrm{K}$ urine, $\mathrm{P}$ blood and $\mathrm{P}$ urine, $\mathrm{Na}$ blood and $\mathrm{K}$ blood, between $\mathrm{Na}$ urine and $\mathrm{P}$ urine and significant negative moderate correlation was determined between K urine and Purine. These findings indicate that metabolism cage housing significantly affects rat's physiological parameters and potentially may influence the animal health and wellbeing.

\section{REFERENCES}

1. Gordon, C.J., Fogelson, L. (1994). Metabolic and thermoregulatory responses of the rat maintained in acrylic or wire-screen cages: implications for pharmacological studies. Physiology \& Behavior 56(1): 73-79.

http://dx.doi.org/10.1016/0031-9384(94)90263-1

2. Kurien, B.T., Everds, N.E., Scofield, R.H. (2004). Experimental animal urine collection: a review Laboratory Animals Ltd. Laboratory Animals 38, 333-361.

http://dx.doi.org/10.1258/0023677041958945 PMid:15479549

3. EU (2010) Directive 2010/63 EU of the European Parliament and of the Council of 22 September 2010 on the protection of animals used for scientific purposes. Official Journal of the European Communities L276, pp. 33-79.

4. Eriksson, E., Royo, F.K, Lyberg Carlsson, H-E., Hau, J. (2004). Effect of metabolic cage housing on immunoglobulin A and corticosterone excretion in faeces and urine of young male rats. Experimental Physiology 89(4): 427-433.

http://dx.doi.org/10.1113/expphysiol.2004.027656 PMid:15131075

5. Heidbreder, C.A., Weiss, I.C., Domeney, A.M., Pryce, C., Homberg, J., Hedou, G., Feldon, J. Moran, M.C., Nelson, P. (2000). Behavioral, neurochemical and endocrinological characterization of the early social isolation syndrome. Neuroscience 100(4): 749-768.

http://dx.doi.org/10.1016/S0306-4522(00)00336-5

6. Krohn, T.C., Hansen, A.K., Dragsted, N. (2003). Telemetry as a method for measuring the impact of housing conditions on rat's welfare. Animal Welfare 12(1): 53-62.

7. Manser, C.E. Morris, T.H., Broom, D.M. (1995). An investigation into the effects of solid or grid cage flooring on the welfare of laboratory rats. Laboratory Animals 29(4): 353-363. http://dx.doi.org/10.1258/002367795780740023 PMid:8558816 
8. Cvek-Hopkins K. (2007). Effect of metabolic cage housing on rodent welfare. SLU Uppsala, 7-9.

9. Yamada, K., Ohki-Hamazaki, H., Wada, K. (2000). Differential effects of social isolation upon body weight, food consumption, and responsiveness to novel and social environment in bombesin receptor subtype-3 (BRS-3) deficient mice. Physiology \& Behavior 68, 555-561. http://dx.doi.org/10.1016/S0031-9384(99)00214-0

10. Balcombe, J.P., Barnard, N.D, Sandusky, C. (2004). Laboratory routines cause animal stress. Contemp Top Lab Anim Sci. 43, 42-51. PMid:15669134

11. Sjaastad, Ø.V., Hove, K., Sand, O. (2003). Physiology of Domestic Animals (pp. 141, 224, 226-227, 241). First edition. Oslo: Scandinavian Veterinary Press.

12. Qiang, D., Salva, A., Sottas, C.M., Niu, E., Holmes, M., Hardy, M.P. (2004). Rapid glucocorticoid mediation of suppressed testosterone biosynthesis in male mice subjected to immobilization stress. Journal of Andrology 25(6): 973-981.

13. Hunt, C., Hambly, C. (2006). Faecal corticosterone concentrations indicate that separately housed male mice are not more stressed than group housed males. Physiology \& Behavior 87, 519-526.

http://dx.doi.org/10.1016/j.physbeh.2005.11.013 PMid:16442135

14. Nagy, T.R., Krzywanski, D., Li, J., Meleth, S., Desmond, R. (2002). Effect of group vs. single housing on phenotypic variance in $\mathrm{C} 57 \mathrm{BL} / 6 \mathrm{~J}$ mice. Obesity Research 10, 412-415.

http://dx.doi.org/10.1038/oby.2002.57

PMid:12006642

15. Spangenberg, E.M.F., Augustsson, H., Dahlborn, K., Essén-Gustavsson, B., Cvek, K. (2005). Housing related activity in rats: effects on body weight, urinary corticosterone levels, muscle properties and performance. Laboratory Animals 39, 45-57. http://dx.doi.org/10.1258/0023677052886457 PMid:15703124

16. D’Arbe, M., Einstein, R., Lavidis, N.A. (2002). Stressful animal housing conditions and their potential effect on sympathetic neurotransmission in mice. The American Journal of Physiology. Regulatory, Intergrative and Comparative Physiology 282, $1422-1428$

http://dx.doi.org/10.1152/ajpregu.00805.2000

PMid:11959685
17. Gil, M.C., Aguirre, J.A., Lemoine, A.P., Segura, E.T., Barontini, M.I. (1999). Influence of age on stress responses to metabolic cage housing in rats. Cellular and Molecular Neurobiologi 19(5): 625-633. http://dx.doi.org/10.1023/A:1006984402291 PMid:10384260

18. Ollson, I.A.S., Westlund, K. (2007).The effect of social factors on behavior and welfare of laboratory rodents and non-human primates. Appl. Anim. Behav. Sci. 103, 229-254. http://dx.doi.org/10.1016/j.applanim.2006.05.022

19. Freymann J., Tsai, P.P., Stelzer, H., Hackbarth, H. (2015). The amount of cage bedding preferred by female BALB/c and $\mathrm{C} 57 \mathrm{BL} / 6$ mice. Lab animal Europe 15 (2): 13-19.

20. Hirsjärvi, P., Väliaho, T. (1995). Gentled and nonhandled Wistar rats in a mildly novel open-field situation. Scandinavian Journal of Laboratory Animal Science 22 (3): 265-269.

21. Van Loo, P.L.P., Kruitwagen, C.L.J.J., Van Zutphen, L.F.M., Koolhaas, J.M., Baumans, V. (2000). Modulation of aggression in male mice: influence of cage cleaning regime and scent marks. Anim Welf. 9, 281-295.

22. Armario, A., Montero, J.L., Balasch, J. (1986). Sensitivity of corticosterone and some metabolic variables to graded levels of low intensity stresses in adult male rats. Physiol Behav. 37, 559-561. http://dx.doi.org/10.1016/0031-9384(86)90285-4

23. Castelhano-Carlos, M.J., Baumans, V. (2009). The impact of light, noise, cage cleaning and in-house transport on welfare and stress of laboratory rats. Laboratory Animals 43, 311-327. http://dx.doi.org/10.1258/la.2009.0080098 PMid:19505937

24. De Boer, S.F., Koopmans, S.J., Slangen, J.L., Van der Gugten, J. (1990). Plasma catecholamine, corticosterone and glucose responses to repeated stress in rats. Effect of interstressor interval length. Physiol Behav 47, 1117-1124. http://dx.doi.org/10.1016/0031-9384(90)90361-7 